\title{
Colorectal micropapillary carcinomas are associated with poor prognosis and enriched in markers of stem cells
}

Hee Jin Lee ${ }^{1}$, Dae-Woon Eom ${ }^{2}$, Gil Hyun $\mathrm{Kang}^{2}$, Sang Hak Han ${ }^{3}$, Gab Jin Cheon ${ }^{4}$, Ho-Suk Oh${ }^{4}$, Koon Hee Han ${ }^{4}$, Heui June Ahn ${ }^{4}$, Hyuk-Jai Jang ${ }^{5}$ and Myoung Sik Han ${ }^{5}$

${ }^{1}$ Department of Pathology, University of Ulsan College of Medicine, Asan Medical Center, Seoul, Korea;

${ }^{2}$ Department of Pathology, University of Ulsan College of Medicine, Gangneung Asan Hospital, Gangneung, Korea; ${ }^{3}$ Department of Pathology, Hallym University Chuncheon Sacred Heart Hospital, Chuncheon, Korea; ${ }^{4}$ Department of Internal medicine, University of Ulsan College of Medicine, Gangneung Asan Hospital, Gangneung, Korea and ${ }^{5}$ Department of Surgery, University of Ulsan College of Medicine, Gangneung Asan Hospital, Gangneung, Korea

Colorectal micropapillary carcinoma has recently been reported as an aggressive variant of adenocarcinoma with a high incidence of lymph node metastasis, but has not been well investigated in terms of survival analysis. This study analyzed the clinicopathological characteristics, including survival data, of the patients with micropapillary carcinoma. We hypothesized that the aggressive features of micropapillary carcinoma might be related to the presence of more tumor cells with stem cell phenotype in colorectal cancer. Fifty-five $(10 \%)$ micropapillary carcinoma cases were identified among 561 cases of colorectal cancer. We compared the clinicopathological characteristics, including survival data and immunohistochemical profiles of stem cell markers (SOX2, NOTCH3, CD44v6, CD166, ALDH1) of micropapillary carcinomas with those of randomly selected 112 conventional adenocarcinomas lacking micropapillary carcinoma components (non-micropapillary carcinoma) in the colorectum. To exclude the possibility of dilution of control group by patients with microsatellite instability-high carcinomas, we divided non-micropapillary carcinomas into microsatellite instability-high carcinoma and microsatellite stable tumors. Micropapillary carcinomas were characterized by more frequent lymphovascular invasion $(P<0.0001)$ and lymph node metastasis $(P<0.0001)$, higher pathological $\mathrm{T}$ and tumor node metastasis stages $(P=0.047$ and $P=\mathbf{0 . 0 0 1})$, and more frequent SOX2 $(P=\mathbf{0 . 0 3 8})$ and NOTCH3 expressions $(P=0.005)$. Overall 5 -year survival rate for patients with micropapillary carcinoma $(37 \%)$ was significantly lower than for microsatellite instability-high carcinoma and microsatellite stable carcinoma patients ( 92 and $72 \%, P<0.0001$ ). The presence of the micropapillary carcinoma component was shown to be associated with a significantly worse survival rate in univariate $(P<0.0001)$ and multivariate $(P=0.003$, Cox hazard ratio 2.402$)$ analyses. In conclusion, recognition of the micropapillary carcinoma component in colonic adenocarcinoma is very important, because the micropapillary carcinoma has been associated with a significantly worse prognosis. We also found a higher expression rate of cancer stem cell markers in micropapillary carcinomas, suggesting their potential contribution to the survival disadvantage of micropapillary carcinoma.

Modern Pathology (2013) 26, 1123-1131; doi:10.1038/modpathol.2012.163; published online 12 October 2012

Keywords: colorectum; micropapillary carcinoma; prognosis; stem cell marker; TNM stage

Colorectal cancer is one of the leading causes of cancer deaths worldwide, and both the prevalence

Correspondence: Dr D-W Eom, MD, PhD, Department of Pathology, University of Ulsan College of Medicine, Gangneung Asan Hospital, 415, Bangdong-ri, Sacheon-myeon, Gangneung-si, Gangwon-do 210-711, Korea.

E-mail:edwjyh@gnah.co.kr

Received 31 January 2012; revised 20 August 2012; accepted 20 August 2012; published online 12 October 2012 and the incidence rate in South Korea are rapidly rising. ${ }^{1}$ For metastatic colorectal cancer, the 5-year survival rate is only about $10 \% .^{2}$ Micropapillary carcinoma is a relatively uncommon and distinctive tumor characterized by small clusters of tumor cells in the clear lacunar spaces, mimicking lymphatic or vascular channels. ${ }^{3}$ Micropapillary carcinoma has high potential to metastasize to the regional lymph node, and has been described in carcinomas from many organs, including the breast, urinary bladder, 
lung, ovary, gall bladder, and stomach. ${ }^{3-7}$ In colorectal carcinoma, micropapillary carcinoma was first reported by $\mathrm{Kim}$ et $a l^{8}$ in 2006. Colorectal micropapillary carcinoma is considered an aggressive variant of adenocarcinoma with a high incidence of lymph node metastasis, but it has not been well investigated in terms of overall and disease-free survivals. Previous published studies found that the proportion of micropapillary carcinoma to the entire tumor ranged from 5 to $80 \%$, and defined micropapillary carcinoma as carcinoma with at least $5 \%$ of micropapillary components. ${ }^{8-11}$

On the other hand, as the identification of tumorinitiating cells, also referred to as cancer stem cells, in acute myeloid leukemia, their presence has also been identified in a number of solid tumor types, such as breast, lung, ovarian, brain, and colon cancer. ${ }^{12-17}$ Emerging evidence suggests that stem cells have a crucial role not only in the embryonic development and maintenance of mature normal tissues, but also in the development of malignancies and disease progression associated with poor prognosis. In fact, the expression of stem cell markers and their prognostic significance have been reported in several solid tumors, including colorectal cancer. ${ }^{16,18-23}$ Several cell surface markers, including CD44, CD133, and CD166, have been used for identification of colorectal cancer stem cells. ${ }^{24-26}$ Activity of aldehyde dehydrogenase 1 (ALDH1), a detoxifying enzyme that oxidizes intracellular aldehydes, has also been used as a colorectal cancer stem cell marker. ${ }^{27}$ We hypothesized that the aggressive features of micropapillary carcinoma might be related to the presence of more tumor cells with stem cell phenotype in colorectal cancer.

In this study, we analyzed the clinicopathological characteristics, including survival of the patients and immunohistochemical profiles of stem cell markers, of 55 cases of micropapillary carcinoma, compared with non-micropapillary carcinoma cases in the colorectum. To exclude the possibility of dilution of control group by patients with microsatellite instability-high carcinomas, which intrinsically have better prognosis, we divided non-micropapillary carcinomas into microsatellite instability-high carcinomas and microsatellite stable tumors. ${ }^{28}$

\section{Materials and methods}

\section{Case Selection}

We selected 561 cases of colorectal adenocarcinoma from the surgical pathology files of the Gangneung Asan Hospital (Gangneung, South Korea), occurring between June 2004 and December 2009. None of the patients had received chemotherapy or radiotherapy before surgery. Hematoxylin and eosin-stained slides from each tumor block were reviewed, and we estimated the percentage of micropapillary carcinoma component in 5\% increments. Fifty-five cases of adenocarcinoma with micropapillary carcinoma characteristics were identified. In particular, we defined micropapillary carcinoma as the occurrence of recognizable, obvious focus or foci of small papillary cell clusters (at least 5\%) lacking true fibrovascular cores, surrounded by empty lacunar spaces.

For comparison, 112 cases of conventional nonmicropapillary colorectal adenocarcinoma with moderately (50-95\% of tumor composed of glands) or poorly differentiated $(49 \%$ or less composed of glands) histology were randomly selected and studied. Patients were staged based on the seventh edition of the AJCC tumor node metastasis (TNM) staging system. ${ }^{29}$ The patients' medical records were reviewed for clinical information, and histological parameters were evaluated on the hematoxylin and eosin-stained slides. The clinicopathological parameters were evaluated in each case, including the patient's age at diagnosis, gender, the primary tumor location, tumor size, grade, invasion depth (pathological (p)T stage), lymphovascular invasion, lymph node metastasis, overall tumor stage, occurrence of other malignancies, operation date, presence or absence of recurrence, most recent follow-up date, and survival status.

\section{Tissue Microarray Construction}

Formalin-fixed, paraffin-embedded tissue samples of micropapillary carcinomas $(n=55)$ and non-micropapillary carcinomas $(n=112)$ were obtained and arrayed using a tissue-arraying instrument (QuickRay, Unitma , Seoul, Korea). Representative areas of each tumor were selected and marked on the hematoxylin and eosin-slide, and its corresponding tissue block was sampled. The designated area of each donor block was punched with a 2-mmdiameter tissue cylinder, and the sample was transferred to a recipient block. Each sample was arrayed to the duplicated blocks to minimize tissue loss.

\section{Immunohistochemistry}

Immunohistochemical staining for SOX2, NOTCH3, CD166, CD44v6, ALDH1, MLH1, MSH2, MSH6, and PMS2 was performed on the arrayed blocks containing micropapillary carcinoma and non-micropapillary carcinoma samples. In equivocal cases, we also stained for D2-40 and factor VIII antigen in the whole tumor section blocks. All immunostainings were performed in the Bond-Max automatic immunostaining device (Leica Biosystem, Newcastle, UK) using a bond polymer intensity detection kit (Leica Biosystem) for formalin-fixed, paraffinembedded tissue sections. Five-micrometerthick sections were obtained by microtome, transferred onto adhesive slides, and dried at $62^{\circ} \mathrm{C}$ for $30 \mathrm{~min}$. Antigen retrieval was carried out in all cases (Table 1). Slides were counterstained with Harris hematoxylin. As positive controls, we used squamous cell carcinoma of the lung for SOX2, 
Table 1 Antibodies used for this study

\begin{tabular}{|c|c|c|c|c|}
\hline Antibody & Source & Location & Dilution & Antigen retrieval \\
\hline SOX2 & Abcam & Cambridge, UK & $1: 500$ & Heat (Citrate), $15 \mathrm{~min}$ \\
\hline NOTCH3 & Abcam & Cambridge, UK & $1: 500$ & Heat (Citrate), $15 \mathrm{~min}$ \\
\hline CD166 & Leica Biosystem & Newcastle, UK & $1: 100$ & Heat (Citrate), $15 \mathrm{~min}$ \\
\hline CD44v6 & Leica Biosystem & Newcastle, UK & $1: 200$ & Heat (Citrate), $15 \mathrm{~min}$ \\
\hline ALDH1 & Abcam & Cambridge, UK & $1: 200$ & Heat (EDTA), $15 \mathrm{~min}$ \\
\hline $\mathrm{D} 2-40$ & DakoCytomation & Glostrup, Denmark & $1: 100$ & Heat (EDTA), $15 \mathrm{~min}$ \\
\hline Factor VIII Antigen & Leica Biosystem & Newcastle, UK & $1: 200$ & Heat (Citrate), $15 \mathrm{~min}$ \\
\hline MLH1 & Leica Biosystem & Newcastle, UK & $1: 200$ & Heat (EDTA), $20 \mathrm{~min}$ \\
\hline MSH2 & Leica Biosystem & Newcastle, UK & $1: 400$ & Heat (EDTA), $20 \mathrm{~min}$ \\
\hline MSH6 & Cell Marque & Hotsprings, USA & 1:100 & Heat (EDTA), $30 \mathrm{~min}$ \\
\hline PMS2 & Cell Marque & Hotsprings, USA & Predilution & Heat (EDTA), $60 \mathrm{~min}$ \\
\hline
\end{tabular}

Abbreviation: ALDH1, aldehyde dehydrogenase 1.

normal liver tissue for ALDH1, peripheral nerve fiber in skin for CD166, breast carcinoma for NOTCH3, and urothelial carcinoma for CD44v6. Negative controls were performed by omitting the primary antibodies.

The SOX2 stains appeared in the tumor nuclei, NOTCH3 appeared in the nuclei and cytoplasm, CD44v6 and CD166 appeared in the cytoplasm and cell membrane, and ALDH1 appeared in the cytoplasm of the neoplastic cells. The results of immunohistochemical staining for each marker were scored based on the intensity of staining as 0 (negative), 1 (weak), 2 (moderate), or 3 (strong), and the percentage of positive epithelial cells in 5\% increments. Receiver-operating characteristic curve analysis against 5-year survival was performed to set the cutoff scores for each marker. ${ }^{30,31}$ Scores above the cutoff were considered positive.

\section{Statistical Analysis}

Data were analyzed using the Statistical Package for the Social Sciences software (version 12.0, SPSS Inc, Chicago, IL, USA). A comparison of means was performed using an unpaired Student's $t$-test. The linearby-association $\chi^{2}$-test and $\chi^{2}$-test were performed to examine associations among categorical variables. Survival analysis was plotted using the KaplanMeyer method, and differences were evaluated using the log-rank test. A multivariate regression analysis (Cox proportional hazards model) with enter method was used to define specific risk factors for overall survival. All $P$ values were two-sided, and statistical significance was accepted when $P<0.05$.

\section{Results}

\section{Clinicopathological Characteristics of Cases}

Of the initial 561 colorectal carcinomas considered, $55(10 \%)$ cases contained $>5 \%$ of micropapillary carcinoma components (Figure 1a). The clinicopathological features of the cases with micropapillary carcinoma (55 cases) and non-micropapillary carci- noma (112 cases) are summarized in Table 2. Microsatellite instability-high carcinoma was defined as loss of expression for at least one of MLH1, MSH2, MSH6, and PMS2, and detected in 15 cases (five with loss of MLH1 expression, eight with loss of MSH2 expression, eight with loss of MSH6 expression, and six with loss of PMS2 expression). ${ }^{32}$ Three of microsatellite instability-high carcinoma cases were micropapillary carcinomas. Postoperative chemotherapy was performed for $87(52 \%)$ out of 167 patients (stage I, $0 \%$; stage II, $34 \%$; stage III, $72 \%$; and stage IV, $70 \%$ ). No primary cancers of other sites were recorded in any cases, except for in two patients, who had concurrent early gastric cancer and thyroid papillary carcinoma, respectively. Twenty-four patients with micropapillary carcinoma were alive at the time of last follow-up. The age of patients with micropapillary carcinoma and non-micropapillary carcinoma ranged from 35 to 88 years (median age, 68 years) and 33 to 93 years (median age, 67 years), respectively. The proportion of the micropapillary carcinoma component in patients with micropapillary carcinoma ranged from 5 to $90 \%$ of total tumor volumes. There was no case that contained pure micropapillary carcinoma component. The micropapillary carcinoma component was frequently mixed with non-micropapillary carcinoma cells and identified in the center, deeper, and peripheral portions of the tumor.

Micropapillary carcinoma samples exhibited a higher level of positive lymphovascular invasion (micropapillary carcinoma, 62\%; microsatellite stable carcinoma, $30 \%$; microsatellite instabilityhigh carcinoma, $8 \% ; P<0.0001)$, more lymph node metastasis (micropapillary carcinoma, 71\%; microsatellite stable carcinoma, 40\%; microsatellite instability-high carcinoma, 33\%; $P<0.0001$ ), and higher stage grouping (stage III-IV; micropapillary carcinoma, $73 \%$; microsatellite stable carcinoma, $40 \%$; microsatellite instability-high carcinoma, $33 \% ; P=0.001$ ) (Table 3 ). The mean number of involved nodes was four in micropapillary carcinomas and two in non-micropapillary carcinomas $(P=0.003)$, whereas the mean number of all nodes examined for micropapillary carcinomas $(N=15)$ 

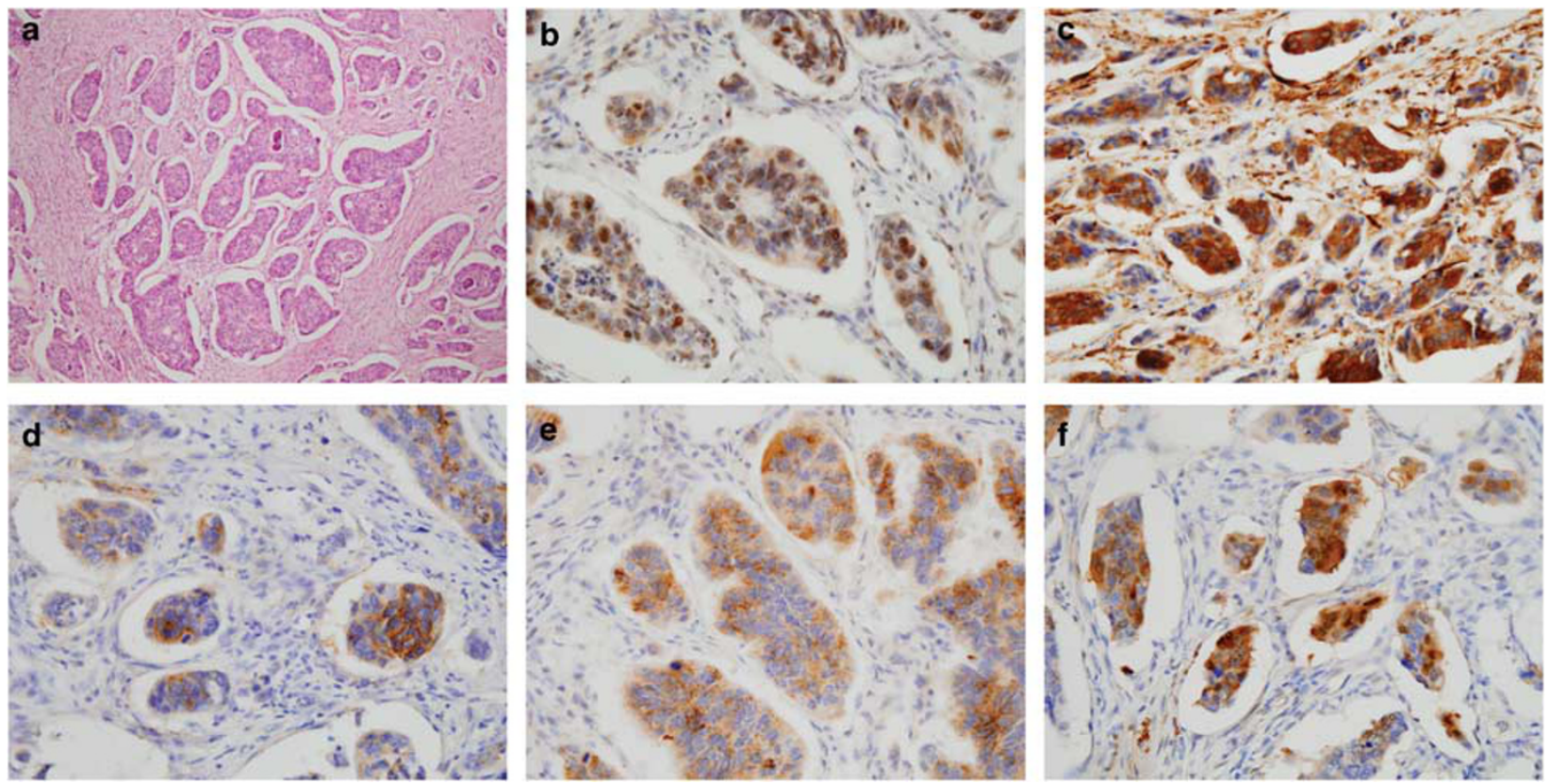

Figure 1 Micropapillary carcinoma histology and immunohistochemical staining. (a) Micropapillary carcinoma components in colorectal carcinoma. (b) Prominent nuclear expression of SOX2 is noted in micropapillary carcinoma. (c) Tumor cells show strong cytoplasmic immunoreactivity for NOTCH3. (d and e) Cytoplasmic and/or membranous expression pattern is identified in CD166 (d) and CD44v6 (e) staining. (f) ALDH1 immunostaining reveals diffuse cytoplasmic pattern.

Table 2 Comparison of clinicopathologic data between micropapillary carcinoma and non- micropapillary carcinoma

\begin{tabular}{|c|c|c|c|c|c|}
\hline \multirow[t]{2}{*}{ Variable } & \multirow[t]{2}{*}{ Characteristics } & \multirow[t]{2}{*}{ Micropapillary carcinoma (\%) } & \multicolumn{2}{|c|}{ Non-micropapillary carcinoma } & \multirow[t]{2}{*}{$\mathrm{P}$} \\
\hline & & & $\begin{array}{c}\text { Microsatellite stable } \\
\text { tumor }(\%)\end{array}$ & $\begin{array}{c}\text { Microsatellite } \\
\text { instabilityhigh tumor (\%) }\end{array}$ & \\
\hline \multirow[t]{2}{*}{ Age (years) } & $<67$ & $23(42)$ & $46(47)$ & $7(58)$ & 0.615 \\
\hline & $\geq 67$ & $32(58)$ & $52(53)$ & $5(42)$ & \\
\hline \multirow[t]{2}{*}{ Gender } & Male & $30(55)$ & $63(64)$ & $10(83)$ & 0.300 \\
\hline & Female & $25(45)$ & $35(36)$ & $2(17)$ & \\
\hline \multirow[t]{2}{*}{ Differentiation } & MD & $54(98)$ & $96(98)$ & $11(92)$ & 1.000 \\
\hline & PD & $1(2)$ & $2(2)$ & $1(8)$ & \\
\hline \multirow[t]{3}{*}{ Location } & Right & $11(20)$ & 11 (11) & $6(50)$ & 0.085 \\
\hline & Left & $18(33)$ & $30(31)$ & $3(25)$ & \\
\hline & Rectum & $26(47)$ & 57 (58) & $3(25)$ & \\
\hline \multirow[t]{2}{*}{ Lymphovascular invasion } & Positive & $34(62)$ & $29(30)$ & $1(8)$ & $<0.0001$ \\
\hline & Negative & 21 (38) & $69(70)$ & $11(92)$ & \\
\hline \multirow[t]{4}{*}{ pT stage } & T1 & $2(4)$ & $2(2)$ & $0(0)$ & 0.047 \\
\hline & T2 & $5(9)$ & 11 (11) & $0(0)$ & \\
\hline & T3 & 35 (63) & $81(83)$ & $11(92)$ & \\
\hline & $\mathrm{T} 4$ & $13(24)$ & $4(4)$ & $1(8)$ & \\
\hline \multirow[t]{2}{*}{ Lymph node metastasis } & Positive & $39(71)$ & $39(40)$ & $4(33)$ & $<0.0001$ \\
\hline & Negative & $16(29)$ & $59(60)$ & $8(67)$ & \\
\hline \multirow[t]{2}{*}{ Distant metastasis } & Positive & 7 (13) & $4(4)$ & $0(0)$ & 0.067 \\
\hline & Negative & $48(87)$ & $94(96)$ & $12(100)$ & \\
\hline \multirow[t]{4}{*}{ TNM stage } & Stage I & $4(7)$ & 11 (11) & $0(0)$ & 0.001 \\
\hline & Stage II & $11(20)$ & $48(49)$ & $8(67)$ & \\
\hline & Stage III & $34(62)$ & $35(36)$ & $4(33)$ & \\
\hline & Stage IV & 6 (11) & $4(4)$ & $0(0)$ & \\
\hline \multirow[t]{2}{*}{ Adjuvant chemotherapy } & Positive & $35(64)$ & $45(46)$ & $5(42)$ & 0.044 \\
\hline & Negative & $20(36)$ & $53(54)$ & $7(58)$ & \\
\hline
\end{tabular}

Abbreviations: MD, moderately differentiated; PD, poorly differentiated; TNM, tumor node metastasis.

and non-micropapillary carcinomas $(N=16)$ did not significantly differ. There were no significant differences between micropapillary carcinoma and nonmicropapillary carcinoma samples with respect to gender or anatomical location.

\section{Immunohistochemical Evaluation}

Tumors with no staining or weak staining intensity were considered negative. Receiver-operating characteristic curve analysis against 5-year survival was 
Table 3 Relationship between the amount of micropapillary component and clinicopathological factors

\begin{tabular}{|c|c|c|c|c|c|c|}
\hline $\begin{array}{l}\text { Micropapillary carcinoma } \\
\text { component }\end{array}$ & Lymphovascular invasion (\%) & $\mathrm{P}$ & Nodal metastasis (\%) & $\mathrm{P}$ & $\begin{array}{l}\text { Distant } \\
\text { metastasis (\%) }\end{array}$ & $\mathrm{P}$ \\
\hline$<5 \%(N=112)$ & $30(27)$ & $<0.0001$ & $44(40)$ & $<0.0001$ & $4(4)$ & 0.055 \\
\hline $5-9 \%(N=15)$ & $7(45)$ & & $8(53)$ & & $2(13)$ & \\
\hline $10-29 \%(N=26)$ & $16(62)$ & & $18(69)$ & & $4(15)$ & \\
\hline$\geq 30 \%(N=14)$ & $11(79)$ & & $13(93)$ & & $1(7)$ & \\
\hline
\end{tabular}

Table 4 Cutoff scores derived from the area under the receiveroperating characteristic curve and frequency of positive expression for immunohistochemistry

\begin{tabular}{lccc}
\hline Marker & $\begin{array}{c}\text { Area under the receiver- } \\
\text { operating curve }\end{array}$ & $\begin{array}{c}\text { Cutoff } \\
\text { score (\%) }\end{array}$ & $\begin{array}{c}\text { Positive } \\
\text { expression (\%) }\end{array}$ \\
\hline SOX2 & 0.558 & 5 & $36(22)$ \\
NOTCH3 & 0.485 & 20 & $81(50)$ \\
CD166 & 0.509 & 20 & $38(23)$ \\
CD44v6 & 0.569 & 5 & $46(28)$ \\
ALDH1 & 0.532 & 20 & $47(30)$ \\
\hline
\end{tabular}

Abbreviation: ALDH1, aldehyde dehydrogenase 1.

performed, and the results are summarized in Table 4. SOX2 expression was more frequently observed in micropapillary carcinoma $(17 / 53,32 \%)$ than in microsatellite stable carcinoma $(16 / 98,16 \%)$ samples $(P=0.038$; Figure $1 \mathrm{~b}$ and Table 5$)$. NOTCH3 expression was also more frequently observed in micropapillary carcinoma $(35 / 51,69 \%)$ than in microsatellite stable carcinoma $(42 / 97,43 \%)$ samples $(P=0.005$; Figure 1c). Although CD166 was more frequently expressed in micropapillary carcinoma $(16 / 52,31 \%)$ than in microsatellite stable carcinoma $(17 / 98,17 \%)$ samples, this difference was not statistically significant (Figure 1d). The difference in CD44v6 expression between micropapillary carcinoma $(18 / 53,34 \%)$ and microsatellite stable carcinoma $(25 / 98,26 \%)$ was also not statistically significant (Figure 1e). ALDH1 expression was not different in micropapillary carcinoma and nonmicropapillary carcinoma groups (Figure 1f).

\section{Survival Analysis}

The median follow-up period for the 167 patients was 54.5 months (range 2-94 months), and 60 patients died of the disease and 66 cases recurred by the end of follow-up. The overall 1, 3, and 5-year survival rates of patients with micropapillary carcinoma were 80,50 , and $37 \%$, respectively, were 94 , 84 , and $72 \%$, respectively, for those with microsatellite stable carcinoma, and were 100, 92, and $92 \%$, respectively, for those with microsatellite instability-high carcinoma. Patients with micropapillary carcinoma had a significantly shorter overall survival than non-micropapillary carcinoma patients $(P<0.0001$; Figure 2a).

The 1,3, and 5-year disease-free survival rates of patients with micropapillary carcinoma were 69,38 ,
Table 5 Summary of immunohistochemical staining

\begin{tabular}{lccc}
\hline & $\begin{array}{c}\text { Micropapillary } \\
\text { Carcinoma (\%) }\end{array}$ & $\begin{array}{c}\text { Microsatellite stable } \\
\text { tumor (\%) }\end{array}$ & $\mathrm{P}$ \\
\hline $\begin{array}{l}\text { SOX2 } \\
\text { Positive }\end{array}$ & $17(32)$ & $16(16)$ & 0.038 \\
Negative & $36(68)$ & $82(84)$ & \\
NOTCH3 & & $42(43)$ & 0.005 \\
Positive & $35(69)$ & $55(57)$ & \\
Negative & $16(31)$ & $17(17)$ & 0.066 \\
CD166 & & $81(83)$ & \\
Positive & $16(31)$ & & \\
Negative & $36(69)$ & $25(26)$ & 0.345 \\
CD44v6 & & $73(74)$ & \\
Positive & $18(34)$ & $32(33)$ & \\
Negative & $35(66)$ & $65(67)$ & \\
ALDH1 & & & \\
Positive & $14(28)$ & & \\
Negative & $37(72)$ & & \\
\hline
\end{tabular}

Abbreviation: ALDH1, aldehyde dehydrogenase 1.

and $33 \%$, respectively; were 92,80 , and $70 \%$, respectively, for microsatellite stable carcinoma patients; and were 100, 92, and $92 \%$, respectively, for microsatellite instability-high carcinoma patients. Patients with micropapillary carcinoma had a significantly shorter disease-free survival than those with non-micropapillary carcinoma $(P<0.0001$; Figure $2 b)$.

When patient survival was further analyzed by TNM stage stratification, the overall 5-year survival rates of stage III colorectal carcinoma patients with micropapillary carcinoma (36\%) were significantly lower than those of microsatellite stable carcinoma patients $(72 \%, P<0.0001)$. Although the overall 5year survival rates of stage I-II colorectal carcinoma patients with micropapillary carcinoma (59\%) were worse than those of microsatellite stable carcinoma patients $(76 \%)$; the difference was not statistically significant $(P=0.554)$. The survival outcome of patients with stage IV carcinoma was not different between micropapillary carcinoma and microsatellite stable carcinoma groups $(P=0.817)$. In stage III, patient survival was further analyzed by application of adjuvant chemotherapy. The overall survival of micropapillary carcinoma patients was not affected by adjuvant chemotherapy $(P=0.719)$. Although statistical significance was not found, microsatellite stable carcinoma patients with adjuvant chemotherapy showed better survival outcome than those without adjuvant therapy ( $P=0.101$, Figure 2c). 

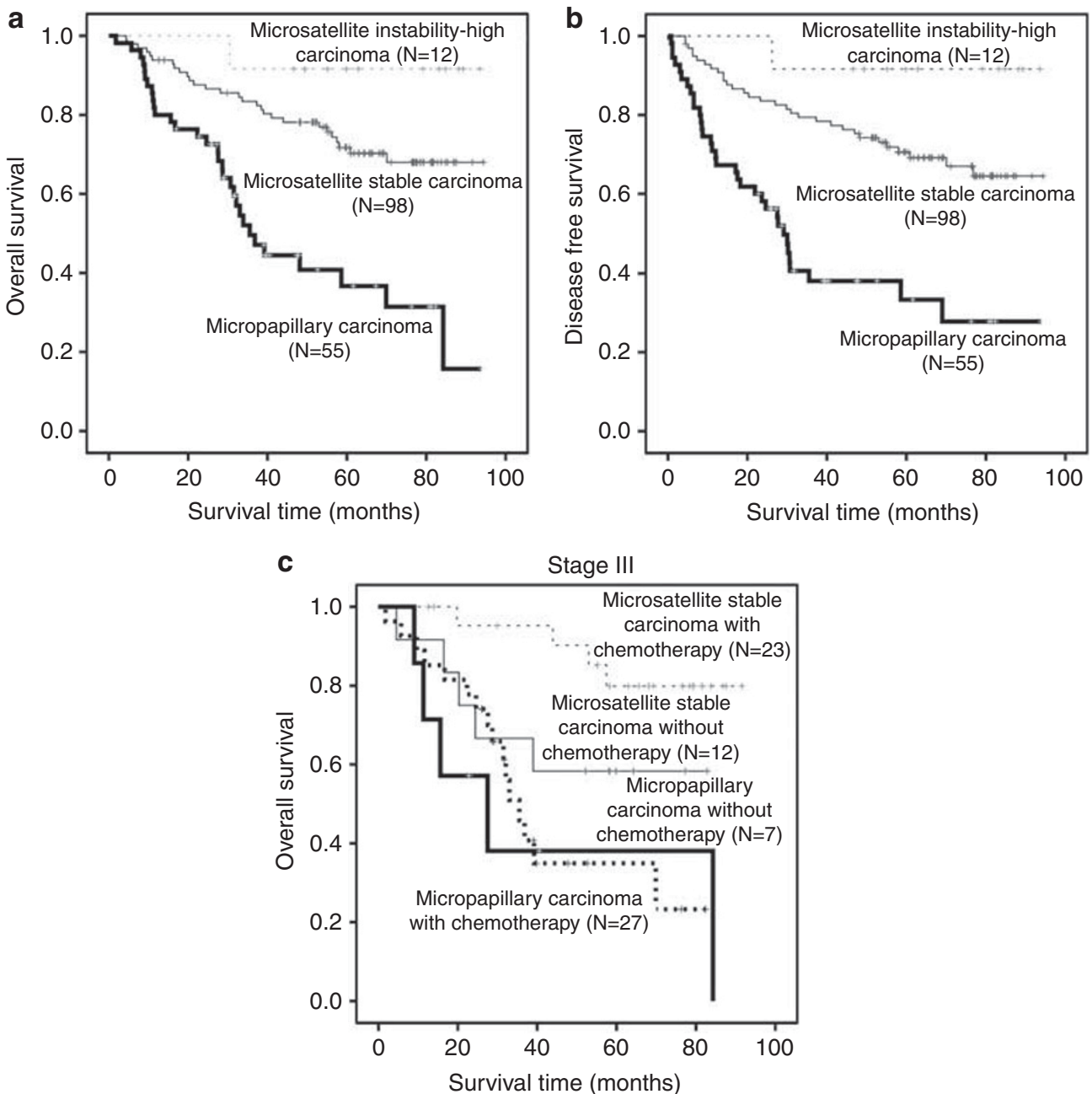

Figure 2 Kaplan-Meier survival analysis (log rank test). (a and b) Non-micropapillary carcinoma patients experience significantly better overall survival rates $(P<0.0001$, a) and disease-free survival rates $(P<0.0001, \mathbf{b})$ than patients with micropapillary carcinoma. (c) In stage III, the overall survival of micropapillary carcinoma patients is not affected by adjuvant chemotherapy $(P=0.719)$. However, microsatellite stable patients with adjuvant chemotherapy show better survival outcome than those without adjuvant therapy $(P=0.101)$.

In addition, the disease-free 5-year survival rates of stage III-IV colorectal carcinoma patients with micropapillary carcinoma $(22 \%)$ were significantly lower than those of microsatellite stable carcinoma patients $(63 \%, P=0.001)$. The disease-free 5-year survival rates of stage I-II colorectal carcinoma patients with micropapillary carcinoma (51\%) were worse than those of microsatellite stable carcinoma patients $(75 \%, P=0.122)$.

The extent of micropapillary carcinoma (the proportion of the micropapillary carcinoma component) in the primary tumors did not affect patient survival (data not shown).

Univariate survival analysis (log rank test) indicated that the factors micropapillary carcinoma, lymphovascular invasion, pT stage, lymph node metastasis, and distant metastasis were associated with a worse prognosis in colorectal carcinomas (Table 6).

Multivariate Cox proportional hazards analyses were performed to identify factors that were independent prognostic predictors of cancer-related death. Micropapillary carcinoma $(P=0.003)$ was an independent prognostic factor for survival (Table 7).

\section{Discussion}

Micropapillary carcinoma showed a distinct histology, characterized by small clusters of tumor cells in the clear lacunar spaces, which has been attributed to reversion of cell polarization. ${ }^{7}$ Several studies showed the prevalence of micropapillary carcinoma was $9-19 \%$ in colorectal carcinoma, and it was associated with aggressive histological features, including higher levels of lymphovascular invasion and perineural invasion, more frequent lymph node and distant metastases, and higher TNM stages (III/ IV).$^{8-11}$ In concordance with previous studies, we identified $10 \%$ of colorectal carcinoma with micropapillary carcinoma component from our cohort (55/561 cases), and micropapillary carcinoma was significantly associated with higher 
Table 6 Univariate analysis for overall survival in colorectal adenocarcinoma

\begin{tabular}{|c|c|c|c|c|}
\hline Variable & Characteristics & $\begin{array}{c}\text { Overall } 5 Y S R \\
(\%)\end{array}$ & s.e. & $\mathrm{P}$ \\
\hline \multirow{2}{*}{$\begin{array}{l}\text { Micropapillary } \\
\text { carcinoma }\end{array}$} & Positive & 37 & 0.079 & $<0.0001$ \\
\hline & Negative & 74 & 0.043 & \\
\hline \multirow[t]{2}{*}{ Age } & $<67$ & 65 & 0.059 & 0.324 \\
\hline & $\geq 67$ & 62 & 0.064 & \\
\hline \multirow[t]{2}{*}{ Gender } & Male & 68 & 0.050 & 0.071 \\
\hline & Female & 56 & 0.065 & \\
\hline \multirow[t]{2}{*}{ Differentiation } & $\mathrm{MD}$ & 63 & 0.040 & 0.577 \\
\hline & $\mathrm{PD}$ & 75 & 0.217 & \\
\hline \multirow[t]{3}{*}{ Location } & Right & 66 & 0.094 & 0.635 \\
\hline & Left & 68 & 0.073 & \\
\hline & Rectum & 60 & 0.055 & \\
\hline \multirow{2}{*}{$\begin{array}{l}\text { Lymphovascular } \\
\text { invasion }\end{array}$} & Positive & 50 & 0.067 & 0.001 \\
\hline & Negative & 71 & 0.048 & \\
\hline Microsatellite & Positive & 87 & 0.088 & 0.055 \\
\hline instability & Negative & 62 & 0.043 & \\
\hline \multirow[t]{4}{*}{ pT stage } & $\mathrm{T} 1$ & 50 & 0.250 & $<0.0001$ \\
\hline & T2 & 73 & 0.138 & \\
\hline & Т3 & 68 & 0.043 & \\
\hline & $\mathrm{T} 4$ & 22 & 0.098 & \\
\hline \multirow{4}{*}{$\begin{array}{l}\text { Lymph node } \\
\text { metastasis } \\
\text { Distant metastasis }\end{array}$} & Positive & 51 & 0.059 & $<0.0001$ \\
\hline & Negative & 73 & 0.050 & \\
\hline & Positive & 0 & 0 & $<0.0001$ \\
\hline & Negative & 68 & 0.040 & \\
\hline \multirow{4}{*}{$\begin{array}{l}\text { Adjuvant } \\
\text { chemotherapy } \\
\text { SOX2 }\end{array}$} & Positive & 58 & 0.057 & 0.355 \\
\hline & Negative & 69 & 0.055 & \\
\hline & Positive & 60 & 0.084 & 0.292 \\
\hline & Negative & 65 & 0.045 & \\
\hline \multirow[t]{2}{*}{ NOTCH3 } & Positive & 66 & 0.056 & 0.880 \\
\hline & Negative & 63 & 0.057 & \\
\hline \multirow[t]{2}{*}{ CD166 } & Positive & 62 & 0.087 & 0.708 \\
\hline & Negative & 65 & 0.045 & \\
\hline \multirow[t]{2}{*}{ CD44v6 } & Positive & 55 & 0.079 & 0.174 \\
\hline & Negative & 68 & 0.046 & \\
\hline \multirow[t]{2}{*}{ ALDH1 } & Positive & 58 & 0.078 & 0.347 \\
\hline & Negative & 67 & 0.048 & \\
\hline
\end{tabular}

Abbreviations: ALDH1, aldehyde dehydrogenase 1; MD, moderately differentiated; PD, poorly differentiated; 5YSR, 5 year survival rate; s.e., standard error.

Table 7 Multivariate analysis for overall survival in colorectal adenocarcinoma

\begin{tabular}{lccc}
\hline Variable & $\begin{array}{c}\text { Cox hazard } \\
\text { ratio }\end{array}$ & $\begin{array}{c}\text { 95\% confidence } \\
\text { interval }\end{array}$ & $\mathrm{P}$ \\
\hline $\begin{array}{l}\text { Micropapillary } \\
\text { carcinoma; positive }\end{array}$ & 2.402 & $1.347-4.282$ & 0.003 \\
$\begin{array}{l}\text { Gender; female } \\
\begin{array}{l}\text { Lymphovascular } \\
\text { invasion; present }\end{array}\end{array}$ & 1.213 & $0.707-2.080$ & 0.483 \\
$\begin{array}{l}\text { Microsatellite } \\
\text { instability; present }\end{array}$ & 1.047 & $0.548-2.001$ & 0.888 \\
$\begin{array}{l}\text { T stage; III-IV } \\
\begin{array}{l}\text { Lymph node metastasis; } \\
\text { present }\end{array}\end{array}$ & 1.220 & $0.474-3.136$ & 0.680 \\
$\begin{array}{l}\text { Distant metastasis; } \\
\text { present }\end{array}$ & 29.680 & $0.883-3.292$ & 0.112 \\
& & $10.682-82.462$ & $<0.0001$ \\
\end{tabular}

levels of lymphovascular invasion, more frequent lymph node metastasis, and higher stage.

Cancer stem cells are defined by their ability to self-renew and generate a progeny of both tumorigenic and non-tumorigenic cancer cells. ${ }^{33}$ With this property, cancer stem cells are thought to be more resistant to chemotherapeutic agents or radiotherapy. ${ }^{34,35}$ Expression of stem cell markers in some tumors has been associated with adverse clinical outcomes. ${ }^{16,18-23}$ Cancer stem cells are also known to have an important role in the process of metastasis. ${ }^{36}$ We found higher expression rates of SOX2, NOTCH3, CD166, and CD44v6 in micropapillary carcinoma than in non-micropapillary carcinoma samples. Fu and colleagues also found that invasive micropapillary carcinoma of the breast showed chemo-resistance and higher prevalence of CD44+/CD24-/low tumor cells, which have been known to have tumor-initiating properties in breast cancer. 37,38

SOX2 belongs to group B of the SOX family, which consists of transcription factors containing a highmobility group of DNA-binding domains that is expressed in a wide variety of tissues, and it has been suggested that it has critical roles in organogenesis, differentiation, and proliferation. ${ }^{39,40}$ Although SOX2 is expressed in embryonal stem cells, a growing body of evidence has revealed the association between SOX2 expression and cancer stem cell properties. Several kinds of tumors, including lung, stomach, breast cancers and gliomas, showed SOX2 overexpression. ${ }^{41-44}$ Recently, two studies demonstrated that SOX2 expression was correlated with lymph node metastasis, distant spread, and poor prognosis in colorectal carcinoma patients. ${ }^{31,45}$

The NOTCH signaling pathway is an evolutionarily conserved intercellular signal transfer system regulating cell differentiation, proliferation, and apoptosis. ${ }^{46}$ This pathway has been identified as a critical system for intrinsic maintenance of colorectal cancer initiating cell self-renewal. ${ }^{47}$ Among the various components of the NOTCH pathway, the activation of NOTCH3 was reported in epithelial ovarian cancer, extrahepatic cholangiocarcinoma, gallbladder cancer, and T-acute lymphoblastic leukemia. ${ }^{23,48,49}$ We found $50 \%$ of colorectal cancer expressed NOTCH3. Compared with non-micropapillary carcinoma, cases with micropapillary carcinoma showed significantly higher levels of NOTCH3 expression (42 vs 69\%).

To the best of our knowledge, only one previous study has investigated the significance of micropapillary carcinoma for survival in colorectal carcinoma. ${ }^{10} \mathrm{Xu}$ et $a 1^{10}$ analyzed 30 colorectal carcinomas with micropapillary component from 1990 to 2000. This study revealed the presence of micropapillary components had an independent importance for survival of colorectal cancer patients, especially in TNM stage I and II. Although patients with micropapillary carcinoma showed worse diseasefree and overall survival rates than those without micropapillary carcinoma in our data, the difference was significant only in stage III cancers. ${ }^{50}$ This discrepancy might be derived from the differences in archived time periods and postoperative treatment. Stage III colorectal cancers are defined as tumors that have metastasized to the lymph node without distant 
metastasis. $^{29}$ The incidence of stage III at presentation ranges between 20 and $30 \% .^{51}$ The 3year disease-free survival in stage III colon cancer without any postoperative chemotherapy ranges between 44 and $52 \% .{ }^{52,53}$ As adjuvant chemotherapy with 5-fluorouracil and levamisole improved disease-free survival and overall survival in stage III colon cancer, adjuvant chemotherapy has been considered as a standard therapeutic modality for this disease. ${ }^{52,54}$ Although postoperative adjuvant chemotherapy was applied to 54 of 75 (72\%) stage III cases, our data showed significantly lower 3-year disease-free survival rates in patients with micropapillary carcinoma than in those without micropapillary carcinoma (50 vs 84\%, $P<0.0001$ ). Poor survival outcomes in stage III patients with micropapillary carcinoma and higher expression of stem cell markers in micropapillary carcinoma might suggest that the presence of more tumor cells with stem-like features in micropapillary carcinoma may be related with chemotherapy resistance.

The limitations of this study include the retrospective nature of the study design and relatively small sample size of the test participants. In addition, fundamental problems of IHC study including subjective scoring system were not completely resolved.

In summary, we examined 561 colorectal carcinomas and identified 55 cases of micropapillary carcinoma. The proportion of micropapillary carcinoma in colorectal carcinoma was small (10\%). Colorectal carcinomas with micropapillary carcinoma showed higher levels of lymphovascular invasion, more frequent lymph node metastasis, and higher stage. The presence of micropapillary carcinoma was associated with lower rates of patient survival through univariate and multivariate analyses. Therefore, we recommend that the presence or absence of micropapillary carcinoma component in colorectal carcinoma should be marked on the pathological report to provide better prognostic information on patients with colorectal carcinoma. We also found a higher expression rate of cancer stem cell markers in micropapillary carcinomas than nonmicropapillary carcinomas. Further studies addressing the relationship between chemo- and/or radiotherapy resistance and the presence of micropapillary carcinoma in colorectal carcinoma are warranted.

\section{Acknowledgements}

This research was funded by the Gangneung Asan Hospital Biomedical Research Center Promotion Fund.

\section{Disclosure/conflict of interest}

The authors declare no conflict of interest.

\section{References}

1 Kwon JH, Choi MG, Lee SW, et al. Trends of gastrointestinal diseases at a single institution in Korea over the past two decades. Gut Liver 2009;3:252-258.

2 Jemal A, Siegel R, Ward E, et al. Cancer statistics, 2007. CA Cancer J Clin 2007;57:43-66.

3 Amin MB, Ro JY, el-Sharkawy T, et al. Micropapillary variant of transitional cell carcinoma of the urinary bladder. Histologic pattern resembling ovarian papillary serous carcinoma. Am J Surg Pathol 1994;18: 1224-1232.

4 Amin MB, Tamboli P, Merchant SH, et al. Micropapillary component in lung adenocarcinoma: a distinctive histologic feature with possible prognostic significance. Am J Surg Pathol 2002;26:358-364.

5 Burks RT, Sherman ME, Kurman RJ. Micropapillary serous carcinoma of the ovary. A distinctive low-grade carcinoma related to serous borderline tumors. Am J Surg Pathol 1996;20:1319-1330.

6 Eom DW, Kang GH, Gang HJ. Micropapillary Carcinoma of the Gallbladder. Korean J Pathol 2008;162-164.

7 Eom DW, Kang GH, Han SH, et al. Gastric micropapillary carcinoma: A distinct subtype with a significantly worse prognosis in TNM stages I and II. Am J Surg Pathol 2011;35:84-91.

$8 \mathrm{Kim}$ MJ, Hong SM, Jang SJ, et al. Invasive colorectal micropapillary carcinoma: an aggressive variant of adenocarcinoma. Hum Pathol 2006;37:809-815.

9 Haupt B, Ro JY, Schwartz MR, et al. Colorectal adenocarcinoma with micropapillary pattern and its association with lymph node metastasis. Mod Pathol 2007;20:729-733.

$10 \mathrm{Xu} \mathrm{F}, \mathrm{Xu}$ J, Lou Z, et al. Micropapillary component in colorectal carcinoma is associated with lymph node metastasis in T1 and T2 Stages and decreased survival time in TNM stages I and II. Am J Surg Pathol 2009;33:1287-1292.

11 Verdu M, Roman R, Calvo M, et al. Clinicopathological and molecular characterization of colorectal micropapillary carcinoma. Mod Pathol 2011;24:729-738.

12 Lapidot T, Sirard C, Vormoor J, et al. A cell initiating human acute myeloid leukaemia after transplantation into SCID mice. Nature 1994;367:645-648.

13 Al-Hajj M, Wicha MS, Benito-Hernandez A, et al. Prospective identification of tumorigenic breast cancer cells. Proc Natl Acad Sci USA 2003;100:3983-3988.

14 Eramo A, Lotti F, Sette G, et al. Identification and expansion of the tumorigenic lung cancer stem cell population. Cell Death Differ 2008;15:504-514.

15 Curley MD, Therrien VA, Cummings CL, et al. CD133 expression defines a tumor initiating cell population in primary human ovarian cancer. Stem Cells 2009;27:2875-2883.

16 Singh SK, Clarke ID, Terasaki M, et al. Identification of a cancer stem cell in human brain tumors. Cancer Res 2003;63:5821-5828.

17 O'Brien CA, Pollett A, Gallinger S, et al. A human colon cancer cell capable of initiating tumour growth in immunodeficient mice. Nature 2007;445:106-110.

18 Horst D, Kriegl L, Engel J, et al. CD133 expression is an independent prognostic marker for low survival in colorectal cancer. Br J Cancer 2008;99:1285-1289.

19 Yan X, Ma L, Yi D, et al. A CD133-related gene expression signature identifies an aggressive glioblastoma subtype with excessive mutations. Proc Natl Acad Sci USA 2011;108:1591-1596. 
20 Chang SH, Worley LA, Onken MD, et al. Prognostic biomarkers in uveal melanoma: evidence for a stem cell-like phenotype associated with metastasis. Melanoma Res 2008;18:191-200.

21 Wang Y, Zhe H, Gao P, et al. Cancer stem cell marker ALDH1 expression is associated with lymph node metastasis and poor survival in esophageal squamous cell carcinoma: a study from high incidence area of northern China. Dis Esophagus 2012;25:560-565.

22 Weichert W, Knosel T, Bellach J, et al. ALCAM/CD166 is overexpressed in colorectal carcinoma and correlates with shortened patient survival. J Clin Pathol 2004;57:1160-1164.

23 Jung SG, Kwon YD, Song JA, et al. Prognostic significance of Notch 3 gene expression in ovarian serous carcinoma. Cancer Sci 2010;101:1977-1983.

24 Chu P, Clanton DJ, Snipas TS, et al. Characterization of a subpopulation of colon cancer cells with stem celllike properties. Int J Cancer 2009;124:1312-1321.

25 Ricci-Vitiani L, Lombardi DG, Pilozzi E, et al. Identification and expansion of human colon-cancer-initiating cells. Nature 2007;445:111-115.

26 Dalerba P, Dylla SJ, Park IK, et al. Phenotypic characterization of human colorectal cancer stem cells. Proc Natl Acad Sci USA 2007;104:10158-10163.

27 Huang EH, Hynes MJ, Zhang T, et al. Aldehyde dehydrogenase 1 is a marker for normal and malignant human colonic stem cells (SC) and tracks SC overpopulation during colon tumorigenesis. Cancer Res 2009;69:3382-3389.

28 Popat S, Hubner R, Houlston RS. Systematic review of microsatellite instability and colorectal cancer prognosis. J Clin Oncol 2005;23:609-618.

29 Edge SB, Byrd DR, Compton CC, et al. (eds) AJCC Cancer Staging Manual. Springer: Chicago, 2009.

30 Zlobec I, Steele R, Terracciano L, et al. Selecting immunohistochemical cut-off scores for novel biomarkers of progression and survival in colorectal cancer. J Clin Pathol 2007;60:1112-1116.

31 Ong CW, Kim LG, Kong HH, et al. CD133 expression predicts for non-response to chemotherapy in colorectal cancer. Mod Pathol 2010;23:450-457.

32 Shia J. Immunohistochemistry versus microsatellite instability testing for screening colorectal cancer patients at risk for hereditary nonpolyposis colorectal cancer syndrome. Part I. The utility of immunohistochemistry. JMol Diagn 2008;10:293-300.

33 Ricci-Vitiani L, Fabrizi E, Palio E, et al. Colon cancer stem cells. J Mol Med (Berl) 2009;87:1097-1104.

34 Eramo A, Ricci-Vitiani L, Zeuner A, et al. Chemotherapy resistance of glioblastoma stem cells. Cell Death Differ 2006;13:1238-1241.

$35 \mathrm{Li} \mathrm{X,} \mathrm{Lewis} \mathrm{MT,} \mathrm{Huang} \mathrm{J,} \mathrm{et} \mathrm{al.} \mathrm{Intrinsic} \mathrm{resistance} \mathrm{of}$ tumorigenic breast cancer cells to chemotherapy. J Natl Cancer Inst 2008;100:672-679.

36 Pang R, Law WL, Chu AC, et al. A subpopulation of CD26 + cancer stem cells with metastatic capacity in human colorectal cancer. Cell Stem Cell 2010;6: 603-615.

37 Chen L, Fan Y, Lang RG, et al. Breast carcinoma with micropapillary features: clinicopathologic study and long-term follow-up of 100 cases. Int J Surg Pathol 2008;16:155-163.

38 Li W, Liu F, Lei T, et al. The clinicopathological significance of CD44+/CD24-/low and CD24 + tumor cells in invasive micropapillary carcinoma of the breast. Pathol Res Pract 2010;206:828-834.

39 Bowles J, Schepers G, Koopman P. Phylogeny of the SOX family of developmental transcription factors based on sequence and structural indicators. Dev Biol 2000;227:239-255.

40 Boiani M, Scholer HR. Regulatory networks in embryoderived pluripotent stem cells. Nat Rev Mol Cell Biol 2005;6:872-884.

41 Gure AO, Stockert E, Scanlan MJ, et al. Serological identification of embryonic neural proteins as highly immunogenic tumor antigens in small cell lung cancer. Proc Natl Acad Sci USA 2000;97:4198-4203.

$42 \mathrm{Li}$ XL, Eishi Y, Bai YQ, et al. Expression of the SRYrelated HMG box protein SOX2 in human gastric carcinoma. Int J Oncol 2004;24:257-263.

43 Rodriguez-Pinilla SM, Sarrio D, Moreno-Bueno G, et al. Sox2: a possible driver of the basal-like phenotype in sporadic breast cancer. Mod Pathol 2007; 20:474-481.

44 Phi JH, Park SH, Kim SK, et al. Sox2 expression in brain tumors: a reflection of the neuroglial differentiation pathway. Am J Surg Pathol 2008;32:103-112.

45 Neumann J, Bahr F, Horst D, et al. SOX2 expression correlates with lymph-node metastases and distant spread in right-sided colon cancer. BMC Cancer 2011;11:518

46 Mitsiadis TA, Hirsinger E, Lendahl U, et al. Deltanotch signaling in odontogenesis: correlation with cytodifferentiation and evidence for feedback regulation. Dev Biol 1998;204:420-431.

47 Sikandar SS, Pate KT, Anderson S, et al. NOTCH signaling is required for formation and self-renewal of tumor-initiating cells and for repression of secretory cell differentiation in colon cancer. Cancer Res 2010; 70:1469-1478.

48 Yoon HA, Noh MH, Kim BG, et al. Clinicopathological significance of altered Notch signaling in extrahepatic cholangiocarcinoma and gallbladder carcinoma. World J Gastroenterol 17:4023-4030.

49 Masiero M, Minuzzo S, Pusceddu I, et al. Notch3mediated regulation of MKP-1 levels promotes survival of T acute lymphoblastic leukemia cells. Leukemia 25: 588-598.

50 Alexe G, Dalgin GS, Scanfeld D, et al. High expression of lymphocyte-associated genes in node-negative HER2 + breast cancers correlates with lower recurrence rates. Cancer Res 2007;67:10669-10676.

51 de Gramont A, Chibaudel B, Bachet JB, et al. From chemotherapy to targeted therapy in adjuvant treatment for stage III colon cancer. Semin Oncol 38: 521-532.

52 Moertel CG, Fleming TR, Macdonald JS, et al. Levamisole and fluorouracil for adjuvant therapy of resected colon carcinoma. N Engl J Med 1990;322: $352-358$.

53 Efficacy of adjuvant fluorouracil and folinic acid in colon cancer. International Multicentre Pooled Analysis of Colon Cancer Trials (IMPACT) investigators. Lancet 1995;345:939-944.

54 Kuebler JP, Wieand HS, O’Connell MJ, et al. Oxaliplatin combined with weekly bolus fluorouracil and leucovorin as surgical adjuvant chemotherapy for stage II and III colon cancer: results from NSABP C-07. J Clin Oncol 2007;25:2198-2204. 